\title{
Chemical grafting of sulfo groups onto carbon fibers
}

Liudmyla M. Grishchenko ${ }^{a *}$, Tetiana M. Bezugla ${ }^{a}$, Anna V. Vakaliuk ${ }^{a}$, Alexander N. Zaderko, Oleksandr V. Mischanchuk ${ }^{\mathrm{b}}$, Tetiana M. Zakharova ${ }^{\mathrm{a}}$, Olga Yu. Boldyrieva ${ }^{\mathrm{a}}$, Vitaliy E. Diyuk ${ }^{\mathrm{a}}$

${ }^{a}$ Department of Chemistry, Taras Shevchenko National University of Kyiv, Volodymyrska Street, 64/13, Kyiv 01601, Ukraine

${ }^{b}$ Chuiko Institute of Surface Chemistry of National Academy of Sciences of Ukraine General Naumov Street 17, Kyiv 03164, Ukraine

liudmyla.grishchenko@gmail.com

Keywords: activated carbon fibers, surface modification, bromination, acidic groups, heterogeneous catalysts, isopropyl alcohol dehydration.

We proposed the brominated carbon cloth that made of polyacrylonitrile-based activated carbon fibers (PAN-ACFs) as a precursor to chemically and uniformly graft $\mathrm{SO}_{3} \mathrm{H}$ groups to prepare the solid acid catalyst. The thermal and catalytic properties of the sulfonated PAN-ACFs were examined by IR controlled catalytic measurements and thermal analysis. The catalytic test results showed that the sulfonated surface remarkably improved the operating efficiency in isopropanol dehydration by decreasing the reaction temperature. All PAN-ACFs with grafted $\mathrm{SO}_{3} \mathrm{H}$ groups prepared through brominated precursors can converse $100 \%$ of isopropanol into propylene at moderate temperature. They showed the highest catalytic activity compared to PAN-ACFs sulfonated with oleum and chlorosulfonic acid, which conversed only $40 \%$ and $70 \%$ of isopropanol into propylene and deactivated at the higher temperatures in the reaction medium.

\section{Introduction}

Carbon cloth and carbon fibers have attracted wide attention because of their excellent multi-functional properties, such as high mechanical strength and advanced thermal stability. Carbon fibers (CF) have the developed surface area, and, so, can act as an adsorbent or solid catalyst [1-4]. Adsorbents and catalysts can be prepared in the most convenient forms for modern technology. These forms include

woven and non-woven materials, textile, fabric, fibers, bands, tows/wisps, and ultra-dispersed powders prepared from crashed and milled fibers. Functional groups of different chemical nature that can be introduced into the surface layer of carbon cloth and carbon fibers. By this introduction, one can vary the surface chemistry of carbon materials [5-7]. In fact, this method is promising for the preparation of advanced 
heterogeneous catalysts with grafted sulfo groups, which are thermostable and hydrolytically stable sites of high acidity [8-10].

The main method to get sulfonated carbon materials is the direct reaction of carbons with oleum and concentrated sulfuric acid [1113]. The highest concentration of sulfo group can be obtained by sulfation of biochars and partially carbonized carbons [14, 15]. However, the catalysts obtained because of such treatment have mechanical characteristics far below that required and low chemical resistance. This situation prevents the use of sulfonated solid carbons for the catalytic liquid-phase reaction that takes place at heating $[14,15]$. The use of catalysts prepared by other methods, in particular, by impregnation of carbon carriers with the necessary components (acids, metal compounds, etc.), is limited by a chemical reaction which takes place at the gas-phase and at the gas-solid interface.

During the reaction in the liquid phase, the elution of the active component can be a reason for the operating efficiency decrease of the catalyst. An urgent task in creating advanced catalysts that based on carbon materials is covalent sulfo groups grafting onto the surface layer, which requires the developing of new modification methods that do not weaken, for example, the carbon textural and other valuable parameters of interest.

One of the most common synthetic approaches in organic synthesis is the use of a halogen-containing precursor, in which halogen atoms can be substituted by various functional groups [16-19]. Much of the literature data is devoted to the bromination of carbon materials, which takes place under rather rigid conditions (in particular, under plasmochemical surface treatment), requires expensive equipment and special conditions for conducting the reaction (plasma cameras, plasma generators, vacuum, etc.) [20-23]. The resulting materials often contain bromine in the form of intercalates or adsorbed bromine, which is not capable of further substitution for other types of functional groups [24-26]. In modern literature, as a rule, the impact of surface treatment on the physical and mechanical properties of the prepared materials is considered. Actual is the changes in the electrical and adhesion parameters. The structural parameters and stability in air, vacuum, and exposed to stress under high humidity and temperature conditions are also studied. At the same time, enough attention is paid to the chemical modification of the surface of carbon materials under mild conditions, in which covalently bonded bromine is active, and it can be substituted by other functional groups.

The present paper is devoted to the bromination of carbon fiber using liquid bromine and aqueous $\mathrm{Br}_{2} \cdot \mathrm{KBr}$ complex. The possibility of using synthesized brominecontaining precursors to produce sulfonated carbon fiber is also explored. 


\section{Experimental part}

Material and methods

We used commercial activated carbon fiber cloth prepared by carbonization and activation of polyacrylonitrile (PAN-ACF). The specific surface area $\left(S_{\mathrm{BET}}\right)$ and the sorption pore volume $\left(V_{\mathrm{S}}\right)$ of the pristine PAN-ACF were $950 \mathrm{~m}^{2} / \mathrm{g}$ and $0.19 \mathrm{~cm}^{3} / \mathrm{g}$, respectively.

The bromination was carried out using two techniques designed to avoid the use of halogenated solvents or solvents that can form strongly adsorbed brominated derivatives. Synthesis

Bromination with $\mathrm{Br}_{2} \cdot \mathrm{KBr}$ solution or liquid bromine: a $5 \mathrm{~g}$ weight sample of PANACF was treated with $50 \mathrm{ml}$ of an aqueous solution containing $10(\mathrm{w} / \mathrm{v}) \mathrm{Br}_{2}$ and 15 mass\% $\mathrm{KBr}$ or $10 \mathrm{ml}$ of $\mathrm{Br}_{2}$ at room temperature for 1 hour. The sample was then treated with $200 \mathrm{ml}$ of a $10 \%(\mathrm{w} / \mathrm{v})$ potassium oxalate solution. When the carbon dioxide gassing was ceased, the brominated PAN-ACF was filtered and washed with water, until no $\mathrm{Br}^{-}$ions registered in the washing waters, and dried in air at $120{ }^{\circ} \mathrm{C}$. The resulting samples were labeled as $\mathrm{PAN}-\mathrm{ACF} / \mathrm{KBr}_{3}$ and $\mathrm{PAN}-\mathrm{ACF} / \mathrm{Br}_{2}$.

For sulfo group grafting, $1 \mathrm{~g}$ of PAN$\mathrm{ACF}, \mathrm{PAN}-\mathrm{ACF} / \mathrm{KBr}_{3}$, or $\mathrm{PAN}-\mathrm{ACF} / \mathrm{Br}_{2}$ were poured into a concentrated solution of sodium mercaptoacetate (MA) or sodium sulfide $(5 \mathrm{ml})$ and kept at $120{ }^{\circ} \mathrm{C}$ for 15 hours. For hydrolysis, the S-derivative PAN-ACFs were washed with $15 \%(\mathrm{v} / \mathrm{v}) \mathrm{HCl}$ and treated with $30 \%(\mathrm{v} / \mathrm{v}) \mathrm{H}_{2} \mathrm{O}_{2}$ for 3 hours. The samples were washed and dried similarly, as described above, and marked as $\mathrm{PAN}-\mathrm{ACF} / \mathrm{X}, \mathrm{PAN}-\mathrm{ACF} / \mathrm{KBr}_{3} / \mathrm{X}$, and $\mathrm{PAN}-$ $\mathrm{ACF} / \mathrm{Br}_{2} / \mathrm{X}$, where $\mathrm{X}=\mathrm{MA}$ or $\mathrm{Na}_{2} \mathrm{~S}$.

Also, the "direct" treatment of PANACF samples with oleum and chlorosulfonic acid was carried out giving $\mathrm{PAN}-\mathrm{ACF} / \mathrm{SO}_{3}$ and $\mathrm{PAN}-\mathrm{ACF} / \mathrm{ClSO}_{3} \mathrm{H}$.

The bromine concentration in the samples was determined by the Volgard method [27]. We subjected the brominated PAN-ACF to oxidative pyrohydrolysis for determination of the total bromine, in the form of bromine ions.

Thermoprogrammed desorption massspectrometry (TPD MS) and thermogravimetry (TGA) were used to characterize the prepared samples. The temperature range of the study was from 30 to $800{ }^{\circ} \mathrm{C}$. The mass-selected profiles were measured at the heating rate of 10 ${ }^{\circ} \mathrm{C} / \mathrm{min}$. By TGA and TPD MS methods, we analyzed the oxidation process that occurred in parallel with bromination.

The mass of carbon oxides (per gram of fibers) which produced at the surface groups' decomposition was estimated by the difference. For such purpose, we estimated the difference between the total mass loss between 200 and $800{ }^{\circ} \mathrm{C}$ found by the TGA method and the bromine content in the samples determined by chemical analysis.

The ratio of desorbed bromine to carbon oxides formed at the decomposition of oxygencontaining surface groups was found by the 
TPD MS method. To determine this ratio, we found the peak area for atomic $\mathrm{Br}^{+}, \mathrm{HBr}^{+}, \mathrm{CO}^{+}$, and $\mathrm{CO}_{2}{ }^{+}$. Taking into account two bromine isotopes $\left({ }^{79} \mathrm{Br}^{+}\right.$and $\left.{ }^{81} \mathrm{Br}^{+}\right)$, we compared the area assigned to $\mathrm{Br}^{+}$with that for $\mathrm{CO}^{+}$and $\mathrm{CO}_{2}^{+}$ peaks.

The total concentration of acid sites $\left(C_{\mathrm{PT}}\right)$ was determined by the titrimetric method by pouring pre-dried PAN-ACF into a $0.1 \mathrm{~N}$ $\mathrm{NaOH}$ solution for one day. According to this method, the concentration of $\mathrm{NaOH}$ in the solution was found before and after contact with the sample. The difference in the concentration of $\mathrm{NaOH}$ found before and after contact is assigned to the total amount of acid sites.

Dehydration of isopropanol vapor was studied in a flow reactor heated from 30 to 250 ${ }^{\circ} \mathrm{C}$ at a heating rate from 5 to $7{ }^{\circ} \mathrm{C} / \mathrm{min}$. The product concentration-propylene concentration was determined by infrared spectrometry at a wavenumber of $3,105 \mathrm{~cm}^{-1}$. As a measure of catalytic activity, the temperature at $100 \%$ conversion of alcohol into propylene $\left(t_{100 \%}\right)$ was chosen.

\section{Results and discussion}

By chemical analysis, we found that bromination, according to proposed methods, caused inclusion of $0.4-0.5 \mathrm{mmol}$ of bromine per gram of PAN-ACF. The bromine content showed no prominent dependence on the bromination methods. By TPD MS, we found an equal content of ionic fragments $\mathrm{m} / \mathrm{z} 80$ and 82 in thermal desorption products $(\mathrm{HBr})$. This ratio is in good agreement with the ratio of naturally occurring isotopes (Figure 1).

According to the data obtained, TPD MS curves for $\mathrm{HBr}^{+}$for both brominated PAN-ACF are similar. The $\mathrm{HBr}$ can desorb in a wide temperature range. The surface sites involved in bromination showed heterogeneity and wide distribution by binding energy.
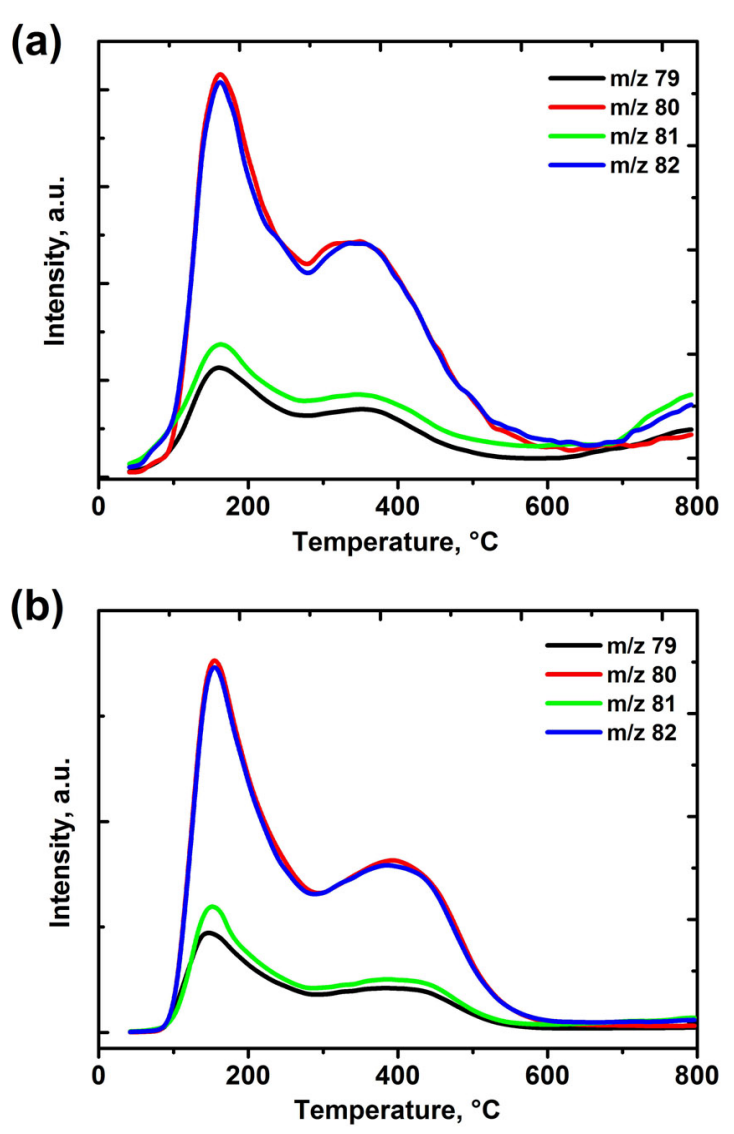

Figure 1. TPD MS profiles m/z 79, 80, 81 and 82 . (a) PAN-ACF/ $/ \mathrm{KBr}_{3}$, (b) PAN-ACF/Br 2 .

Thermodesorption of $\mathrm{HBr}$ takes place in $90-300$ and $300-590^{\circ} \mathrm{C}$ ranges. The thermodesorption peaks are at $150-160{ }^{\circ} \mathrm{C}$ and $350-380{ }^{\circ} \mathrm{C}$, respectively (Figure 1). In addition, TPD MS spectra recorded signals that showed bromine desorption. But, since they are like the temperature profile of $\mathrm{HBr}$, this means the formation of $\mathrm{Br}^{+}$as a result of $\mathrm{HBr}$ dissociation in the 
ionization camera of the mass-spectrometer, not because of the decomposition of some other types of Br-containing groups on the surface fibers.

(a)

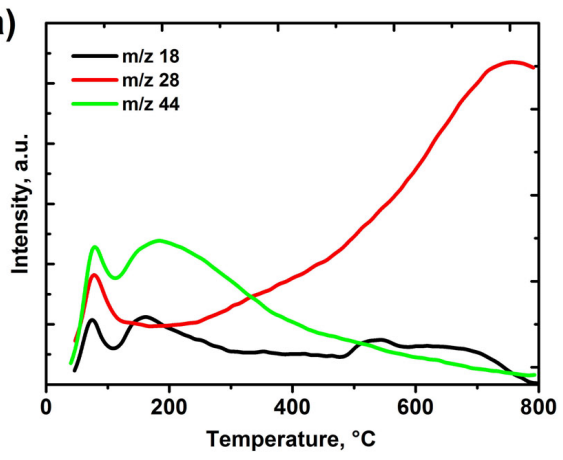

(b)

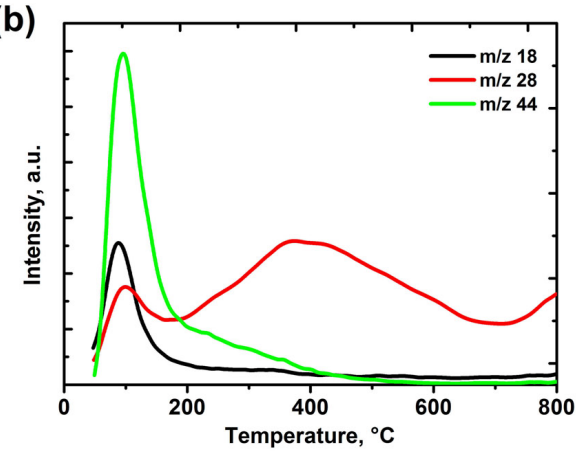

(c)

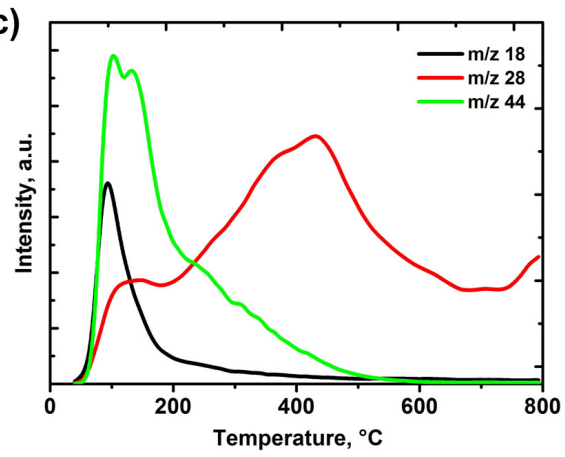

(d)

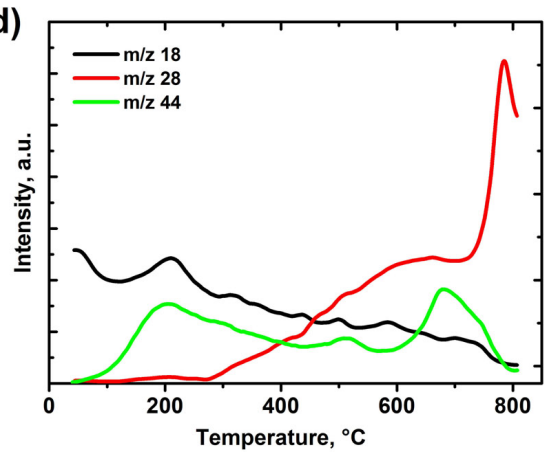

Figure 2. TPD MS profiles $\mathrm{m} / \mathrm{z} 18,28$, and 44 . (a) PAN-ACF, (b) PAN-ACF/ $\mathrm{KBr}_{3}$, (c) PAN-ACF/Br 2 , (d) $\mathrm{PAN}-\mathrm{ACF} / \mathrm{Br}_{2} / \mathrm{Na}_{2} \mathrm{~S}$.
TPD MS data showed small amounts of $\mathrm{CO}$ and $\mathrm{CO}_{2}$ released at the heating of the pristine PAN-ACF (Figure 2a). This observation is explained by the small content of the oxygen-containing groups. The decomposition of high-temperature phenolic groups accompanies the release of $\mathrm{CO}$ at above $550{ }^{\circ} \mathrm{C}$ [28]. The thermal desorption curves were fitted by the Gaussian functions to separate $\mathrm{CO}$ and $\mathrm{CO}_{2}$. We found that carboxyl groups in the small quantity can be registered between 100 and $300{ }^{\circ} \mathrm{C}$. The anhydride and lactone groups are decomposed at temperatures between 350 and $550{ }^{\circ} \mathrm{C}$.

These assignments are in good agreement with the temperature ranges of decompositions reported in [28,29]. According to the potentiometric titration, the total number of all oxygen-containing surface groups in PAN$\mathrm{ACF}$ is about $0.92 \mathrm{mmol} / \mathrm{g}$.

Bromination leads to noticeable surface oxidation, as evidenced by the change in the shape and the release intensity of $\mathrm{CO}, \mathrm{CO}_{2}$, and $\mathrm{H}_{2} \mathrm{O}$ (Figures 2b and 2c). Because of the parallel oxidation, low-temperature $\mathrm{CO}$ and $\mathrm{CO}_{2}$ sites are formed on the surface of the brominated PAN-ACF. The intensive $\mathrm{CO}$ desorption between 300 and $500{ }^{\circ} \mathrm{C}$ at the peak temperature of $430{ }^{\circ} \mathrm{C}$ corresponds to the anhydride and lactone groups [28,29]. High amounts of phenolic groups in the brominated PAN-ACF were registered by high-temperature desorption of $\mathrm{CO}$. The release of $\mathrm{CO}_{2}$ in the 
temperature range of $100-300{ }^{\circ} \mathrm{C}$ is a piece of evidence that bromination caused the intensive formation of carboxyl groups. According to TGA, for PAN-ACF, a small weight loss $(6.5 \%)$ took place between 30 and $850{ }^{\circ} \mathrm{C}$ because of the decomposition of the oxygen-containing groups (Figure 3). For brominated PAN-ACF, weight loss losses are significant as compared to the pristine PAN-ACF. A new peak appears in the DTG curves between 180 and $320{ }^{\circ} \mathrm{C}$. In this temperature range, TPD MS showed desorption of low-temperature bromine (Figure 3). We registered three TG/DTG effects for $\mathrm{PAN}-\mathrm{ACF} / \mathrm{Br}_{2}$ and $\mathrm{PAN}-\mathrm{ACF} / \mathrm{KBr}_{3}$ (Figure 3). The first effect corresponds to physisorbed $\mathrm{H}_{2} \mathrm{O}$.
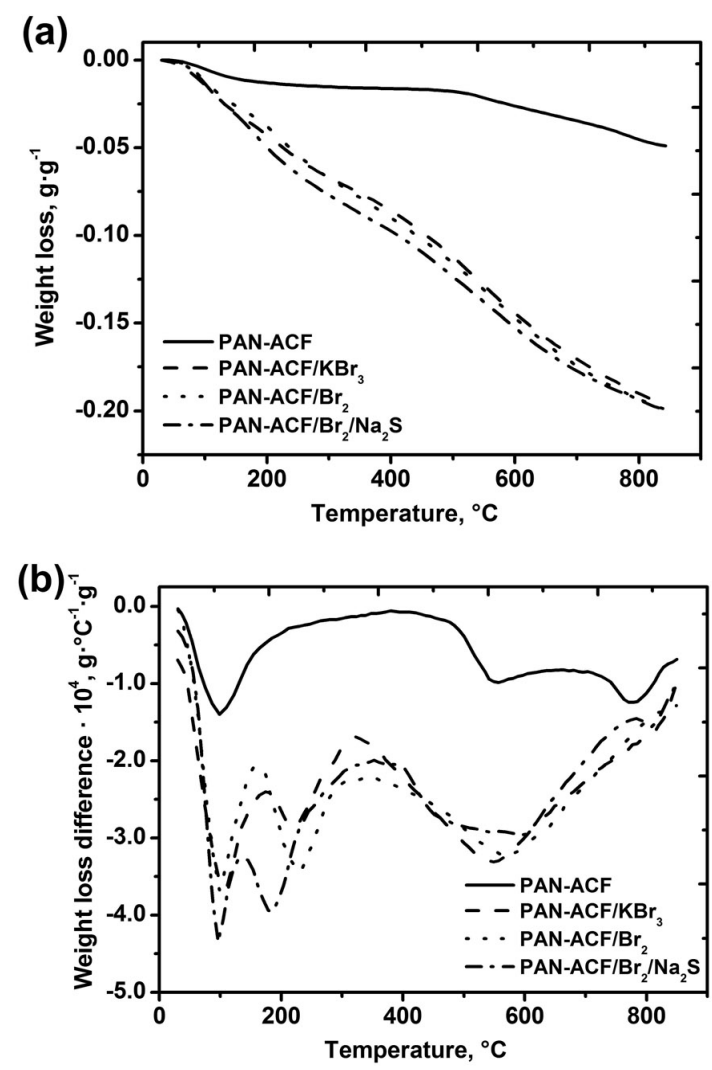

Figure 3. TGA: TG (a) and DTG (b).

The peak temperature at water desorption $t_{\text {des, } \max }$ is $95 \pm 25^{\circ} \mathrm{C}$. In fact, the decomposition of the low-temperature $\mathrm{Br}$ corresponds to the second effect observed in the temperature range $180-320^{\circ} \mathrm{C}$ with $t_{\text {des, } \max }$ about $220-230{ }^{\circ} \mathrm{C}$. The third effect corresponds to the high-temperature desorption of $\mathrm{Br}$ and $\mathrm{CO}$ between 330 and $850^{\circ} \mathrm{C}, t_{\text {des, } \max }=555 \pm 15$ ${ }^{\circ} \mathrm{C}$. If compare TPD MS and TGA data for the brominated PAN-ACF, one can see that compared with the pristine PAN-ACF, the maximum of water desorption shifted on 30-50 ${ }^{\circ} \mathrm{C}$ in the high-temperature region. The adsorbed water amount is increased up to 1.7 times for $\mathrm{PAN}-\mathrm{ACF} / \mathrm{KBr}_{3}$ and more than twice times for $\mathrm{PAN}-\mathrm{ACF} / \mathrm{Br}_{2}$. Both brominated PAN-ACF have higher surface hydrophilicity than the pristine PAN-ACF.

According to the data of TGA, the weight loss about $0.21 \mathrm{~g}$ corresponds to the release of $\mathrm{CO}$ produced by the parallel oxidation for the brominated PAN-ACF. Surface oxidation does not depend on the chosen bromination method, although the oxidation of PAN$\mathrm{ACF} / \mathrm{Br}_{2}$ occurs to a lesser extent. These observations are also confirmed by the TPD MS method.

$\mathrm{PAN}-\mathrm{ACF} / \mathrm{Br}_{2}$ and $\mathrm{PAN}-\mathrm{ACF} / \mathrm{KBr}_{3}$ that are prepared by using both methods contain approximately the same amount of bromine. The temperature range and temperatures at the bromine desorption peak determined by TPD MS and TGA are consistent with each other. These parameters are not very different for both samples. But for PAN-ACF/ $\mathrm{Br}_{2}$, they are $10-30$ 
${ }^{\circ} \mathrm{C}$ higher. In both cases, thermal desorption of bromine occurs in wide temperature range, showing high thermal stability of bromine, and, on the possibility of its substitution by other types of functional groups.

Sulfo groups were found for $\mathrm{PAN}-\mathrm{ACF} / \mathrm{Br}_{2}$ and $\mathrm{PAN}-\mathrm{ACF} / \mathrm{KBr}_{3}$ subjected to sulfonation, by sulfidation, followed by hydrolysis and oxidation. According to the TPD MS data, the pyrolysis of the surface layer in the temperature range of $90-800{ }^{\circ} \mathrm{C}$ is accompanied by the release of $\mathrm{SO}_{2}$ gas (Figure 4). We recorded m/z 64 and $\mathrm{m} / \mathrm{z} 48$ channels, which are typical for $\mathrm{SO}_{2}^{+}$and $\mathrm{SO}^{+}$ions that registered for the decomposition of sulfo groups [30]. Both temperature profiles are synchronous. However, the signal at $\mathrm{m} / \mathrm{z} 48$ has a much lower intensity. This is because the formation of $\mathrm{SO}^{+}$owing to the dissociation of $\mathrm{SO}_{2}{ }^{+}$in the source of mass spectrometer.

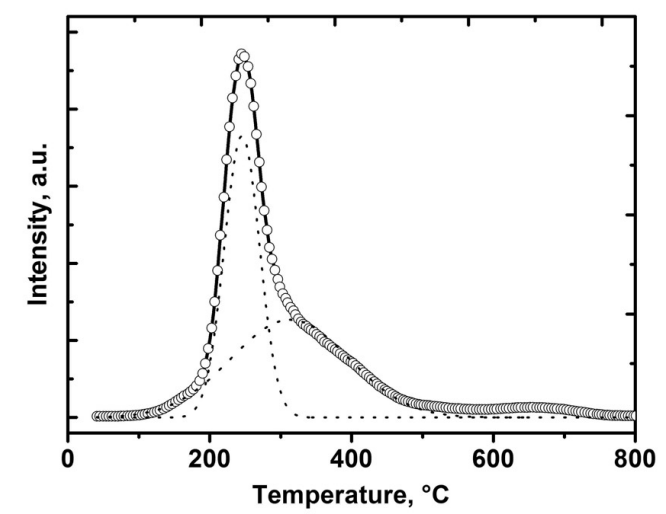

Figure 4. Typical TPD MS profile $\mathrm{m} / \mathrm{z} 64$ PAN$\mathrm{ACF} / \mathrm{Br}_{2} / \mathrm{Na}_{2} \mathrm{~S}$.

Gaussian functions showed two main components having peak temperatures at 240 and $330{ }^{\circ} \mathrm{C}$ (Figure 4). Different peak temperatures proved that the sulfo groups had a difference in the nearest neighbor groups. The curves of the thermal desorption of $\mathrm{CO}$ and $\mathrm{H}_{2} \mathrm{O}$ for the sulfur-containing samples are not very different from that of the pristine PAN-ACF (Figure 2d).

As compared to $\mathrm{PAN}-\mathrm{ACF} / \mathrm{Br}_{2}$ and $\mathrm{PAN}-$ $\mathrm{ACF} / \mathrm{KBr}_{3}$ for the sulfonated PAN-ACF, the number of oxygen-containing (phenolic) groups which thermal decomposition product is $\mathrm{CO}$ registered at temperatures above $600{ }^{\circ} \mathrm{C}$.

Chemical analysis shows no bromine in $\mathrm{PAN}-\mathrm{ACF} / \mathrm{KBr}_{3} / \mathrm{MA}, \mathrm{PAN}-\mathrm{ACF} / \mathrm{Br}_{2} / \mathrm{MA}, \mathrm{PAN}-$ $\mathrm{ACF} / \mathrm{KBr}_{3} / \mathrm{Na}_{2} \mathrm{~S}$, and $\mathrm{PAN}-\mathrm{ACF} / \mathrm{Br}_{2} / \mathrm{Na}_{2} \mathrm{~S}$. Found from the TG/DTG curves, the weight loss peaked between 130 and $370{ }^{\circ} \mathrm{C}$ is referred to the thermal decomposition of sulfo groups and desorption of $\mathrm{SO}_{2}$ gas (Figure 3). The temperature at the $\mathrm{SO}_{2}$ desorption peak is $\sim 230$ $\pm 50^{\circ} \mathrm{C}$ (Table 1). This fact is confirmed by the data of TPD MS, showing a significant release of $\mathrm{SO}_{2}$ within this temperature interval. However, in this temperature range besides $\mathrm{SO}_{2}$, we registered $\mathrm{CO}$ desorption, which takes place because of the thermal decomposition of various oxygen-containing groups formed by oxidation of sulfur-containing fibers with $\mathrm{H}_{2} \mathrm{O}_{2}$ at the last stage of modification (Figure 2d). The oxygencontaining groups whose thermal desorption occurs in the form of $\mathrm{CO}_{2}$ can be attributed predominantly to carboxyl groups, and groups that are desorbed with the release of $\mathrm{CO}$ and $\mathrm{CO}_{2}$, e.g., to lactone and anhydride groups $[28,29]$. So, the effect of weight loss in the 
mentioned range refers to the decomposition of both strong acidic sulfo groups and weak acidic oxygen-containing groups.

According to obtained TG/DTG data, the total amount of acidic groups for PAN$\mathrm{ACF} / \mathrm{KBr}_{3} / \mathrm{MA}, \quad \mathrm{PAN}-\mathrm{ACF} / \mathrm{Br}_{2} / \mathrm{MA}, \quad \mathrm{PAN}-$ $\mathrm{ACF} / \mathrm{KBr}_{3} / \mathrm{Na}_{2} \mathrm{~S}$, and $\mathrm{PAN}-\mathrm{ACF} / \mathrm{Br}_{2} / \mathrm{Na}_{2} \mathrm{~S}$ ranged from 0.049 to $0.068 \mathrm{~g} / \mathrm{g}$. These values are greater than that for PAN-ACF/MA and PAN-ACF/Na $2 \mathrm{~S}$ (Table 1).

The TG/DTG data agrees well with the results obtained by potentiometric titration, since $C_{\mathrm{PT}}$ ranged from 1.34 to $2.08 \mathrm{mmol} / \mathrm{g}$. For PAN-ACF/MA and PAN-ACF/Na $2 \mathrm{~S}, C_{\mathrm{PT}}$ is 1.04 and $1.17 \mathrm{mmol} / \mathrm{g}$, respectively. The weight loss effect found between 130 and $370{ }^{\circ} \mathrm{C}$ ranged from 0.034 to $0.038 \mathrm{~g} / \mathrm{g}$. So, the concentration of acidic groups in the prepared the sulfonated PAN-ACF does not depend on the bromination method, but depends on the sulfating agent. In all cases, treatment with sodium sulfide gave a larger number of acid groups than with sodium mercaptoacetate. The studied sulfonated PANACF can be ranged in the following sequence by the acid groups' content:

PAN-ACF $/ \mathrm{Br}_{2} / \mathrm{Na}_{2} \mathrm{~S}>\mathrm{PAN}-\mathrm{ACF} / \mathrm{KBr}_{3} / \mathrm{Na}_{2} \mathrm{~S}>$ $\mathrm{PAN}-\mathrm{ACF} / \mathrm{Br}_{2} / \mathrm{MA}>\mathrm{PAN}-\mathrm{ACF} / \mathrm{SO}_{3}>\mathrm{PAN}-$ $\mathrm{ACF} / \mathrm{KBr}_{3} / \mathrm{MA}>\mathrm{PAN}-\mathrm{ACF} / \mathrm{ClSO}_{3} \mathrm{H}>\mathrm{PAN}-$ $\mathrm{ACF} / \mathrm{Na}_{2} \mathrm{~S}>\mathrm{PAN}-\mathrm{ACF} / \mathrm{MA}$.

For samples sulfated with oleum and chlorosulphonic acid, the amount of acid groups takes a value up to $1.5 \mathrm{mmol} / \mathrm{g}$. This situation takes place mainly because of the strong oxidation of the carbon fiber surface with the aforementioned strong oxidizing agents. Accompanying the sulfation, the oxidation reaction passes in parallel on the carbon surface. This tandem process caused the introduction of not only sulfo groups, but the oxygencontaining groups of different types. The weight loss curves and the total weight loss for the brominated and sulfonated PAN-ACF are similar. For some sulfonated PAN-ACF, this parameter is somewhat higher, which is associated with the formation of a significant amount of oxygen-containing groups at the last preparation stage at oxidation by $\mathrm{H}_{2} \mathrm{O}_{2}$. Chemical transformations of the surface layer when bromine-containing precursors treated with sulfur-containing compounds can be summarized by the following scheme (Figure 5). The addition of bromine to double $\mathrm{C}=\mathrm{C}$ bonds with the formation of bromine precursor (II) results from bromination of PAN-ACF (I).

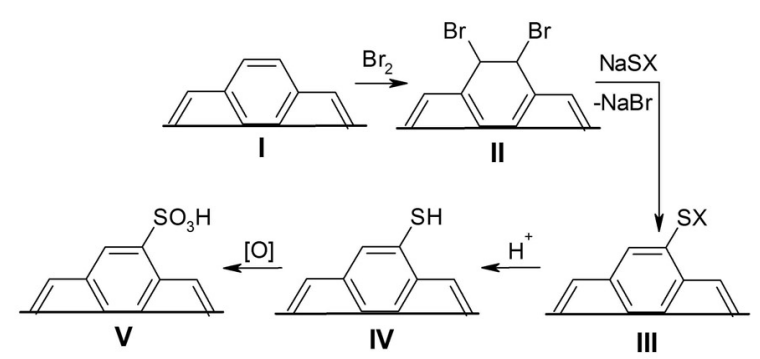

Figure 5. Scheme of bromination and sulfonation.

The sulfidation agent reacts with (II) splitting of bromine and the renewal of the conjugate structure of $\mathrm{C}=\mathrm{C}$ bonds (products IIIa and IIIb). We suggested that at acidification, the surface groups (III) interact with hydrochloric acid and giving (IV). The oxidation of (IV) caused the 
formation of sulfo groups (V). The direct reaction of PAN-ACF occurs similarly, as proposed above.

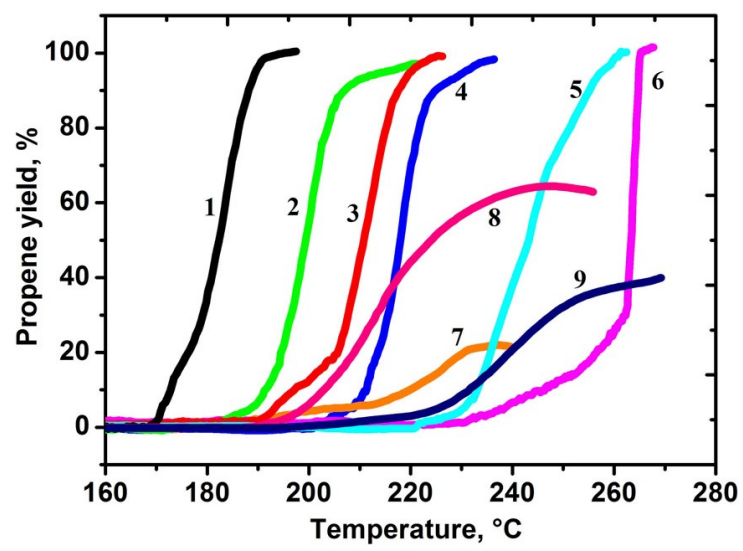

Figure 6. Propylene yield against temperature: 1 - PAN-ACF/ $/ \mathrm{Br}_{2} / \mathrm{Na}_{2} \mathrm{~S}, 2$ - PAN-ACF $/ \mathrm{KBr}_{3} / \mathrm{Na}_{2} \mathrm{~S}$, 3 - PAN-ACF/Br $/ \mathrm{BA}_{2}, 4-\mathrm{PAN}-\mathrm{ACF} / \mathrm{KBr}_{3} / \mathrm{MA}$, 5 - PAN-ACF/Na $2 \mathrm{~S}, 6$ - PAN-ACF/MA, 7 - PAN-ACF, 8 - $\mathrm{PAN}-\mathrm{ACF} / \mathrm{SO}_{3}, 9$ - $\mathrm{PAN}-\mathrm{ACF} / \mathrm{ClSO}_{3} \mathrm{H}$.

Preliminary bromination involves surface sites into the grafting of sulfo groups for the most. We chose gas-phase dehydration of isopropanol to be a model reaction to test the catalytic activity.

Figure 6 shows the temperature dependences for propylene yield. For all catalyst that contains sulfo groups, there is a complete conversion of isopropanol to propylene. Apparently, the PAN-ACF/Br$/ \mathrm{Na}_{2} \mathrm{~S}$ and PAN$\mathrm{ACF} / \mathrm{KBr}_{3} / \mathrm{Na}_{2} \mathrm{~S}$ showed the highest catalytic activity. We observed the lowest efficiency for $\mathrm{PAN}-\mathrm{ACF} / \mathrm{SO}_{3}$ and $\mathrm{PAN}-\mathrm{ACF} / \mathrm{ClSO}{ }_{3} \mathrm{H}$ catalysts. The acidity shows a positive correlation with the catalytic activity and $t_{100 \%}$ (Table 1). The total propylene conversion over the high-active catalysts reached at 195 and 220 ${ }^{\circ} \mathrm{C}$, respectively. However, only $5 \%$ conversion of isopropanol into propylene is registered over the pristine PAN-ACF under these conditions.

Table 1. Temperature range $(\Delta t)$, peak temperature $\left(t_{\max }\right)$ of $\mathrm{SO}_{3} \mathrm{H}$ group desorption, weight loss in the $\Delta t$ range $\left(\Delta m_{\Delta t}\right)$, the total acidity, from potential titration $\left(C_{\mathrm{PT}}\right)$, temperature at the beginning $\left(t_{\mathrm{b}}\right)$ and at $100 \%$ conversion of isopropanol into propylene $\left(t_{100 \%}\right)$.

\begin{tabular}{|l|c|c|c|c|c|c|}
\hline Catalysts & $\Delta t,{ }^{\circ} \mathrm{C}$ & $t_{\text {max }}{ }^{\circ} \mathrm{C}$ & $\Delta m_{\Delta \mathrm{t}}, \mathrm{g} / \mathrm{g}$ & $C_{\mathrm{PT}}, \mathrm{mmol} / \mathrm{g}$ & $t_{\mathrm{b}},{ }^{\circ} \mathrm{C}$ & $t_{100 \%},{ }^{\circ} \mathrm{C}$ \\
\hline PAN-ACF/SO & $140-290$ & 210 & 0.030 & 1.49 & 190 & $240^{*}$ \\
\hline PAN-ACF/ClSO & & & \\
\hline PAN-ACF/MA & $140-330$ & 205 & 0.050 & 1.32 & 200 & $270^{* *}$ \\
\hline PAN-ACF/KBr $/ \mathrm{MA}$ & $185-350$ & 285 & 0.034 & 1.04 & 230 & 265 \\
\hline PAN-ACF/Br $/ \mathrm{MA}$ & $190-370$ & 230 & 0.049 & 1.34 & 200 & 235 \\
\hline PAN-ACF/ $\mathrm{Na}_{2} \mathrm{~S}$ & $170-330$ & 200 & 0.055 & 1.46 & 190 & 225 \\
\hline PAN-ACF/ $/ \mathrm{KBr}_{3} / \mathrm{Na}_{2} \mathrm{~S}$ & $130-340$ & 200 & 0.038 & 1.17 & 220 & 260 \\
\hline PAN-ACF/Br $/ \mathrm{Na}_{2} \mathrm{~S}$ & $150-370$ & 210 & 0.068 & 2.08 & 170 & 195 \\
\hline
\end{tabular}

*Propylene yield is $70 \%$. **Propylene yield is about $40 \%$.

For PAN-ACF/ $\mathrm{Br}_{2} / \mathrm{Na}_{2} \mathrm{~S}$ and PAN- $\mathrm{ACF} / \mathrm{Na}_{2} \mathrm{~S}$. This difference is about $30-40{ }^{\circ} \mathrm{C}$ if $\mathrm{ACF} / \mathrm{KBr}_{3} / \mathrm{Na}_{2} \mathrm{~S}$, the temperatures at $t_{100 \%}$ are we compared $\mathrm{PAN}-\mathrm{ACF} / \mathrm{Br}_{2} / \mathrm{MA}$ and PANlower by $40-65{ }^{\circ} \mathrm{C}$ compared with that of $\mathrm{PAN}-\quad \mathrm{ACF} / \mathrm{KBr}_{3} / \mathrm{MA}$. The presence of a small 
quantity of various oxygen-containing groups, as sites of moderate acidity, can explain the low catalytic activity of the PAN-ACF, about 20\% propylene yield. Among them, the highest acidity has carboxyl groups, which are involved in the dehydration reaction. Since their acidity is much less than sulfo groups, we did not register the total conversion of alcohol into the reaction products over the pristine fibers. We registered incomplete conversion of alcohol to propylene over $\mathrm{PAN}-\mathrm{ACF} / \mathrm{SO}_{3}$ and $\mathrm{PAN}-\mathrm{ACF} / \mathrm{ClSO}_{3} \mathrm{H}$ catalysts. The maximal propylene yield was found at a high temperature of 240 and $270{ }^{\circ} \mathrm{C}$, correspondingly. So, the reaction of brominecontaining samples with sulfating reagents followed oxidation gave catalysts which have high operating efficiency in the dehydration reaction. Using bromine-containing precursors leads to introducing many sulfo groups into the surface layer, in contrast to direct sulfonation of the pristine fiber. The sulfo groups grafted with sodium sulfide supplied advanced catalytic activity. The bromine-containing precursors make it possible to create more active heterogeneous catalysts, than the usage of the direct methods, in particular, the treatments with oleum and chlorosulfonic acid.

\section{Conclusions}

We prepared the sulfonated PAN-ACFs from the brominated surface precursors. Sulfurcontaining functional groups have high thermal stability, and respective sulfonated PAN-ACFs catalysts showed a high total content of sulfo groups in the surface layer. These advanced solid acid catalysts in contrast to PAN-ACFs sulfonated by oleum and chlorosulfonic acids have high activity and not deactivating at the higher temperatures in the reaction medium.

\section{References}

[1] Roldán L, Pires E, Fraile JM, García-Bordejé E. Impact of sulfonated hydrothermal carbon texture and surface chemistry on its catalytic performance in esterification reaction. Catal Today 2015;249:153-160.

[2] $\mathrm{Hu} \mathrm{L}$, Lin $\mathrm{L}, \mathrm{Wu} \mathrm{Z}$, Zhou S, Liu S. Chemocatalytic hydrolysis of cellulose into glucose over solid acid catalysts. Appl Catal B-Environ 2015;174175:225-43.

[3] Wan J-G, Zhan Y-Y, Wang Y, Zhu L-W, Cui H-Y, Yi W-M. Catalytic fructose dehydration to 5hydroxymethylfurfural over sulfonated carbons with hierarchically ordered pores. J Fuel Chem Technol 2016; 44(1):1341-8.

[4] Grishchenko LM. Diyuk VE. Konoplitska OP. Lisnyak VV. Maryichuk RT. Modeling of copper ions adsorption onto oxidative-modified activated carbons. Adsorpt Sci Technol 2017;35(9-10): 884-900.

[5] Radkevich VZ. Senko TL. Wilson K. Grishenko LM. Zaderko A Diyuk VY. The influence of surface functionalization of activated carbon on palladium dispersion and catalytic activity in hydrogen oxidation. Appl Catal A: Gen 2008;335(2):241-51.

[6] Grishchenko LM, Vakaliuk AV, Diyuk VE, Lisnyak VV. From destructive $\mathrm{CCl}_{4}$ adsorption to grafting $\mathrm{SO}_{3} \mathrm{H}$ groups onto activated carbon fibers. Mol Cryst Liq Cryst 2018;673(1):1-15.

[7] Bezugla T, Grishchenko L, Vakaliuk A, Zaderko A, Diyuk V. Activated carbon fibers modified with sulfurcontaining functional groups. Proceedings of the 7th International Conference on Nanomaterials: Applications and Properties (NAP); 2017 Sep 10-15; Zatoka, Ukraine. New York: IEEE Press; 2017. 
[8] Calle Cdela, Fraile JM, García-Bordejé E, Pires E, Roldán L. Biobased catalyst in biorefinery processes: sulphonated hydrothermal carbon for glycerol esterification Catal Sci Technol 2015;5:2897-903.

[9] Nakhate AV, Yadav GD. Synthesis and Characterization of Sulfonated Carbon-Based Graphene Oxide Monolith by Solvothermal Carbonization for Esterification and Unsymmetrical Ether Formation. ACS Sustain Chem Eng 2016;4:1963-73.

[10] Diyuk VE, Grishchenko LN and Yatsimirskii VK. Kinetics of the dehydration of 2propanol on modified activated charcoal containing acid sites. Theor Exp Chem 2008;44(5):331-7.

[11] Moa X, Lopez DE, Suwannakarn K, Liu Y, Lotero E, Goodwin JrJG, Lu CJ. Activation and deactivation characteristics of sulfonated carbon catalysts. J Catal 2008;254:332-8.

[12] Dehkhoda AM, West AH, Ellis N. Biochar based solid acid catalyst for biodiesel production. Appl Catal A: Gen 2010;382:197-204.

[13] Nakajima K, Hara M. Amorphous Carbon with $\mathrm{SO}_{3} \mathrm{H}$ Groups as a Solid Brønsted Acid Catalyst. ACS Catal 2012;2(7):1296-304.

[14] Hara M, Yoshida T, Takagaki A, Takata T, Kondo JN, Hayashi S, Domen KA. A carbon matrial as a strong protonic acid. Angew Chem Int Edit 2004;43(22): 2955-8.

[15] Toda M, Takagaki A, Okamura M, Kondo JN, Hayashi S, Domen KA, Hara M. Biodisel made with sugar catalyst. Nature 2005;438(10):178.

[16] Multian VV, Kinzerskyi FE, Vakaliuk AV, Grishchenko LM, Diyuk VE, Boldyrieva OYu, Kozhanov VO, Mischanchuk OV, Lisnyak VV, Gayvoronsky VYa. Surface response of brominated carbon media on laser and thermal excitation: optical and thermal analysis study. Nanoscale Res Lett 2017;12:146.

[17] Diyuk VE, Zaderko AN, Veselovska KI, Lisnyak VV. Functionalization of surface of carbon materials with bromine vapors at mediate high temperature: a thermogravimetric study. J Therm Anal Calorim 2015;120:1665-78.

[18] Do Nascimento GM, Hou T, Kim YA, Muramatsu H, Hayashi T, Endo M, Akuzawa N, Dresselhaus MS. Double-wall carbon nanotubes doped with different $\mathrm{Br}_{2}$ doping levels: a resonance Raman study. Nano Lett 2008;8:4168-72.

[19] Georgakilas V, Otyepka M, Bourlinos AB, Chandra B, Kim N, Kemp KC, Hobza P, Zboril R, Kim KS. Functionalization of graphene: covalent and noncovalent approaches: Derivatives and applications. Chem Rev 2011;112(11):6156-214.

[20] Friedrich JF, Hidde G, Lippitz A, Unger WES. Plasma bromination of graphene for covalent bonding of organic molecules. Plasma Chem Plasma Process 2013;34(3):621-45.

[21] Wettmarshausen S, Kühn G, Hidde G, Mittman HU, Friedrich JF. Plasma-chemical bromination of graphitic materials and its use for subsequent functionalization and grafting of organic molecules. Plasma Processes Polym 2007;4(9):832-9.

[22] Friedrich JF, Wettmarshausen S, Hanelt S, Mach R, Mix R, Zeynalov EB, Meyer-Plath A. Plasma chemical bromination of graphitic materials and its use for subsequent functionalization and grafting of organic molecules. Carbon 2010;48:3884-94.

[23] Bezugla TM, Grishchenko LM, Vakaliuk AV, Diyuk VE, Mischanchuk OV, Lisnyak VV. Covalent bonding of sulfogroups to activated carbon fibers: the role of bromine plasma pretreatment. Mol Cryst Liq Cryst 2018;661:58-67.

[24] Gaier JR, Ditmars NF, Dillon AR. Aqueous electrochemical intercalation of bromine into graphite fibers. Carbon 2005;43:189-93.

[25] Jaworske DA, Gayer JR, Maciag C and Slabe ME. Differential scanning calorimetric survey of brominated PAN: pitch-based and vapor-grown fibers. Carbon 1987;25:779-82.

[26] Mathur RB, Bahl OP, Kannan A, Flandrois S, Marchand A and Gijpta V. In situ electrical resistivity 
changes during bromine intercalation in carbon fibers.

Carbon 1996;34:1215-20.

[27] ISO 1841-1:1996.

[28] Figueiredo JL, Pereira MFR, Freitas MMA and Orfao JJM. Modification of the surface chemistry of activated carbon. Carbon 1999;37:1379-89.

[29] Diyuk VE, Mariychuk RT, Lisnyak VV. Barothermal preparation and characterization of micromesoporous activated carbons. Textural studies, thermal destruction and evolved gas analysis with TG-TPD-IR technique. J Therm Anal Calorim 2016;124:1119-30.

[30] Diyuk VE, Mariychuk RT, Lisnyak VV. Functionalization of activated carbon surface with sulfonated styrene as a facile route for solid acids preparation. Mater Chem Phys 2016;184:138-45. 